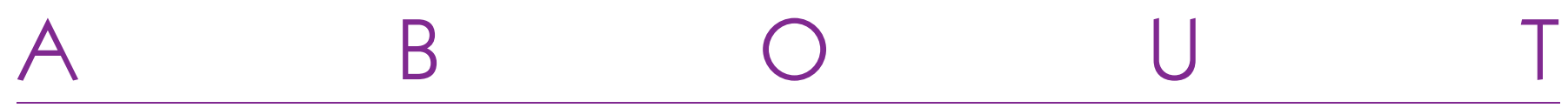

\title{
The first scientific clinical study
}

\section{James Lind, London, 1753}

\section{Michel AMORIC}

Just 25 years after Pierre Fauchard published his pioneering work, The Surgeon Dentist or Treatise on the Teeth in 1728, James Lind, a Scottish physician, presented the results of his study on scurvy, the first clinical experiment in the history of medicine, which provided the methodological foundation for modern medicine.

This malady, recognized some 400 years $\mathrm{BC}$, was known to attack, selectively, troops in isolated garrisons. In 1536, Jacques Cartier observed that Indians in the Saint Laurent basin, who were immune to this scourge, regularly drank concoctions made from the needles of coniferous trees. So he gave it to his sailors who were then immunized against scurvy, not knowing, of course, that it was the high level of vitamin $C$ in the beverage that was the active factor. About a century later John Woodall of the British East India Company noted in his 1617 book The Surgeon's Mate that lemon juice helped prevent the disease and then, in 1734, the Dutch writer Johann Bachstrom, stated that "Scurvy is exclusively caused by a lack of fresh vegetables in the diet.

But it was James Lind, a British Navy surgeon, who codified his observations into the first clinical medical trial in scientific history. During a long voyage Lind selected 12 men from the crew, all suffering from scurvy, and divided them into six pairs,

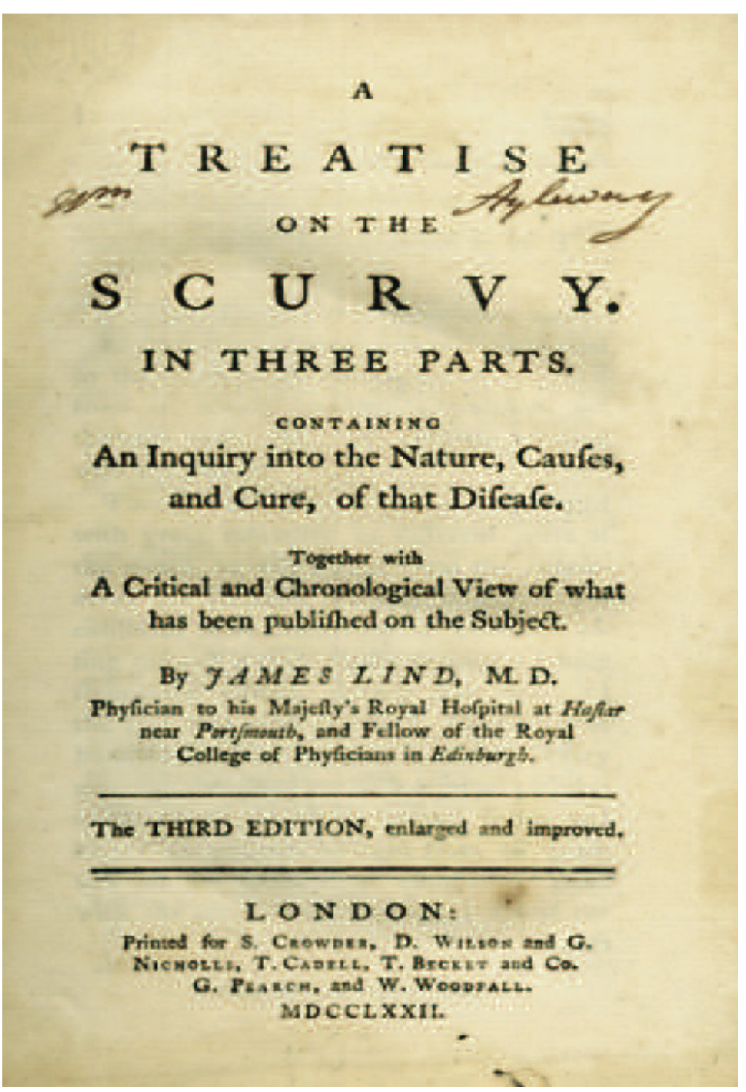


Chap.IV. Of the prevention of the fearys. 149

The following are the experiments.

On the 20 th of $M \circ y$ 1747, I feleated twelve patients in the feurvy, on board the Salifony at fea. Their cales were as fimilar as I could have them. They all in general had putrid gums, the fpots and lafitude, with weaknefs of their knecs. They lay together in one place, being a proper spartment for the fick in the fore-beld; and had one diet common to all, viz, watergroel fweetened with fugar in the morning 3 frefh mutton-broth often times for dimer; at other times light puddings, boiled bifeuit with fugar, $\mathcal{E}_{c}$, and for fupper, barley and raifins, rice and currants, fago and wine, or the like. Two of thefe were ordered each a quart of eyder a-day. Two others took twenty-five drops of shisir vitribl, three times a-day, upon an empty ftomach; ufing a gargle of it for their months. T wo others took two fpoonfuls of vinegar three times a-day, upos an elajty flomach; having their gruels and their other food tharpencd with vinegar, as alfo the gargle for their mouth. Two of the worf patients, with the tendons in the ham quite rigid (a fymptom none of the reft had) were put under a courfe of fea-water. Of this they drank half a pint every day, and fometimes more or lefs, as it operated, by way of gentle phyfic. Two others had each two ofanges and one lemon given them every day, Thefe

$$
\text { L. } 3 \text { they }
$$

giving each group different additions to their basic diet. Some took cider, another pair seawater, and others a mixture of garlic, mustard and horseradish or spoonful's of vinegar. But the test couple ate two oranges and lemons. They experienced a remarkable recovery and the design of test group and control group had been brilliantly introduced. Lind presented vi ADVERTISEM!ENT.

might perhaps have been expected from an infpcolion of feveral thoufand feorbutic patients, from a perufal of ercry book publifled on the fubject, and from an extanive correfpondence with mon parts of the world, whereby a knowiedge muft have been obtained of every remarkable occurrence in this fifeafe; but, though a few partial facts and obforvations may, for a Hitle, flatter with hopes of greater fuceef, yet exore enlarged experience mult ever evinee the fallacy of all pofitive affertion: in the healing ant.

$$
\begin{aligned}
& \text { Ef molus in ribus, } \\
& \text { Stut corti Anigue furr. }
\end{aligned}
$$

Hifer Helpe:

An: 50,172 .

his results in this Treatise of 1753. Here are the relevant sections of the original document:

\section{Of the Prevention of the Scurvy}

I shall conclude the precepts relating to the preservation of seamen with showing the best means of obviating 
many inconveniences which attend long voyages and of removing the several causes productive of this mischief.

The following are the experiments.

On the 20th May, 1747, I took twelve patients in the scurvy on board the Salisbury at sea. Their cases were as similar as I could have them. They all in general had putrid gums, the spots and lassitude, with weakness of their knees. They lay together in one place, being a proper apartment for the sick in the fore-hold; and had one diet in common to all, viz., water gruel sweetened with sugar in the morning; fresh mutton broth often times for dinner; at other times puddings, boiled biscuit with sugar etc.; and for supper barley, raisins, rice and currants, sago and wine, or the like. Two of these were ordered each a quart of cyder a day. Two others took twenty five gutts of elixir vitriol three times a day upon an empty stomach, using a gargle strongly acidulated with it for their mouths. Two others took two spoonfuls of vinegar three times a day upon an empty stomach, having their gruels and their other food well acidulated with it, as also the gargle for the mouth. Two of the worst patients, with the tendons in the ham rigid la symptom none the rest had) were put under a course of sea water. Of this they drank half a pint every day and sometimes more or less as it operated by way of gentle physic. Two others had each two oranges and one lemon given them every day. These they eat with greediness at different times upon an empty stomach. They continued but six days under this course, having consumed the quantity that could be spared. The two remaining patients took the bigness of a nutmeg three times a day of an electuray recommended by an hospital surgeon made of garlic, mustard seed, rad. raphan., balsam of Peru and gum myrrh, using for common drink narley water well acidulated with tamarinds, by a decoction of which, with the addition of cremor tartar, they were gently purged three or four times during the course.

The consequence was that the most sudden and visible good effects were perceived from the use of the oranges and lemons; one of those who had taken them being at the end of six days fit four duty. The spots were not indeed at that time quite off his body, nor his gums sound; but without any other medicine than a gargarism or elixir of vitriol he became quite healthy before we came into Plymouth, which was on the 16th June. The other was the best recovered of any in his condition, and being now deemed pretty well was appointed nurse to the rest of the sick...

As I shall have occasion elsewhere to take notice of the effects of other medicines in this disease, I shall here only observe that the result of all my experiments was that oranges and lemons were the most effectual remedies for this distemper at sea. I am apt to think oranges preferable to lemons, though it was principally oranges which so speedily and surprisingly recovered Lord Anson's people at the Island of Tinian, of which that noble, brave and experienced commander was so sensible that before he left the island one man was ordered on shore from each mess to lay in a stock of them for their future security. ... Perhaps one 
history more may suffice to put this out of doubt.

"Eft modus in rebus

Sunt certi denique fines"

(There is a measure in things; there are, moreover, certain limits

Horace, Satires I. 1. 106.)
James LIND. A Treatise on the Scurvy in Three Parts. Containing an inquiry into the Nature, Causes, and Cure of that Disease, together with a Critical and Chronological View of what has been published on the subject. A. Millar, London, 1753. 